\title{
Role of duodenal lipid and cholecystokinin A receptors in the pathophysiology of functional dyspepsia
}

\author{
C Feinle, O Meier, B Otto, M D’Amato, M Fried
}

\begin{abstract}
Backgroundlaims-We aimed to evaluate the role of fat and cholecystokinin (CCK) in the pathophysiology of functional dyspepsia (FD) by investigating symptoms and plasma CCK levels following increasing doses of duodenal lipid during gastric distension, and the effect of CCK-A receptor blockade.

Subjects/methods-In study A, six FD patients were studied on three occasions during duodenal infusion of saline or lipid (1.1 (L-1) or $2 \mathrm{kcal} / \mathrm{min}(\mathrm{L}-2)$ ) and proximal gastric distensions. Six healthy subjects were also studied as controls during L-2 only. In study $B$, the effect of the CCK-A antagonist dexloxiglumide $(5 \mathrm{mg}$ / $\mathrm{kg} / \mathrm{h}$ ) on L-2 induced symptoms was studied in 12 FD patients. Changes in gastric volume at minimal distending pressure and plasma CCK (study A) were assessed, gastric distensions were performed using a barostat, and dyspeptic symptoms were monitored.
\end{abstract}

Results-Lipid increased gastric volume compared with saline $(\Delta \mathrm{V}(\mathrm{ml})$ : saline 15 (20), L-1 122 (42), L-2 114 (28)) in patients and even more so in controls (221 (37); $\mathbf{p}<0.05)$. During distensions, symptoms were greater during $\mathbf{L}-2$ than during saline or $\mathbf{L - 1}$, and greater in patients than in controls, while gastric compliance was smaller in patients than in controls $(p<0.05)$. Lipid increased plasma CCK levels in patients and controls $(p>0.05)$. Dexloxiglumide abolished the increase in gastric volume $(\Delta \mathrm{V}(\mathrm{ml})$ : dexloxiglumide 17 (9), placebo 186 (49)) and dyspeptic symptoms (sum of scores: dexloxiglumide 24 (7), placebo 44 (19)) during duodenal lipid infusion. Dexloxiglumide also reduced gastric compliance $(\mathrm{ml} / \mathrm{mm} \mathrm{Hg}$ : dexloxiglumide 51 (7), placebo 72 (11)) and symptoms (sum of scores: dexloxiglumide 101 (17), placebo 154 (21)) during gastric distension.

Conclusion-CCK-A receptors are involved in the generation of dyspeptic symptoms by duodenal lipid during gastric distension.

(Gut 2001;48:347-355)

Keywords: functional dyspepsia; duodenal lipid; cholecystokinin; dyspeptic symptoms

Dr C Feinle,

Gastroenterology Division,

University Hospital Zurich,

Rämistr. 100, 8091 Zurich,

Switzerland.

Accepted for publication 25 September 2000 painful at smaller intragastric volumes and lower pressures compared with healthy subjects. In addition to mechanical stimulation by food, the gastrointestinal tract is also stimulated chemically by nutrients. There is now accumulating evidence that nutrients, particularly foods containing fat, play an important role in the generation of dyspeptic symptoms. ${ }^{4-6}$ We have previously shown that duodenal infusion of lipid exacerbates the hypersensitivity to distension in patients with functional dyspepsia. Moreover, combining gastric balloon distension with duodenal lipid infusion reproduced dyspeptic symptoms in these patients. ${ }^{7}$ This effect appears to be specific for fat as infusion of an isocaloric glucose solution into the duodenum did not induce the same symptomatic response. ${ }^{8}$ The specificity of this response for fat suggests involvement of cholecystokinin (CCK), as CCK is released mainly by the presence of fat in the small intestine. ${ }^{9}$ CCK is regarded as a satiety hormone ${ }^{10}$ and has also been implicated in the induction of nausea in healthy humans. ${ }^{11}$ In addition, we have previously found evidence for involvement of CCK in lipid induced nausea in a study in healthy subjects. ${ }^{12}$ The nausea experienced during distension of the proximal stomach and duodenal infusion of lipids was improved by pretreatment with the CCK-A receptor antagonist loxiglumide. Intravenous administration of CCK has been shown to reproduce symptoms in patients with functional dyspepsia, and symptoms were relieved by oral administration of loxiglumide. ${ }^{13}$ It is therefore possible that CCK dependent mechanisms underlie dyspeptic symptoms that occur in response to fat ingestion.

The aim of this study was therefore to investigate the effect of the CCK-A receptor antagonist dexloxiglumide on symptom development during duodenal lipid infusion and gastric distension in patients with functional dyspepsia, and to assess the effect on patient sensitivity to gastric distension. Specifically, we wished to investigate the hypothesis that duodenal lipid would induce symptoms in patients with functional dyspepsia by releasing CCK, and that these symptoms could be alleviated using a CCK-A receptor antagonist. In addition, we studied the relationship between increasing doses of duodenal lipid during gastric distension, plasma CCK levels, and severity of symptoms.

Abbreviations used in this paper: FD, functional dyspepsia; CCK, cholecystokinin; MDP, minimal distending pressure; VAS, visual analogue scale; AUC, area under the curve. 


\section{Subjects and methods}

SUBJECTS

Twelve patients (10 women, two men; aged 22-61 years) with functional dyspepsia (for criteria see below) and six healthy subjects (five women, one man; aged 23-49 years) were included in the studies. All subjects were of normal body weight for height (BMI: patients 21 (1) $\mathrm{kg} / \mathrm{m}^{2}$; healthy subjects 20 (1) $\mathrm{kg} / \mathrm{m}^{2}$ ), non-smokers, and were not receiving any medication during the course of the study. The study was carried out with the approval of the ethics committee at the University Hospital Zürich. All subjects gave informed written consent prior to participation.

Subjects with functional dyspepsia were recruited from the staff and students of the University of Zurich via an email describing the symptomatic criteria required for entry into the study. In a telephone interview, patients were selected for further investigation depending on the presence and severity of symptoms. $\mathrm{Pa}-$ tients had at least three of the following symptoms for more than six months, of at least a moderate severity: postprandial fullness/early satiety, bloating, epigastric pain, and nausea/ vomiting. Severity was scored on a $0-3$ scale with 0 representing "symptoms not experienced", 1 "slight symptoms, but not troublesome", 2 "moderate symptoms, troublesome, but not impairing daily activities", and 3 "severe symptoms, impairing daily activities". Patients who had previously undergone gastrointestinal surgery or were receiving medications that could not be discontinued for the duration of the study were excluded from the study.

Each patient underwent laboratory tests, upper gastrointestinal endoscopy, ultrasound, and a ${ }^{13} \mathrm{C}$ urea breath test for determination of Helicobacter pylori status. If all investigations were negative, the patient was admitted into the study. Healthy subjects had to have no history of gastrointestinal disease and no experience of any symptoms suggestive of dyspepsia. Each subject was required to visit the laboratory once before the start of the study. During this visit, subjects were familiarised with the requirements of the study, the gastric (barostat) tube, study procedures, and symptom questionnaires. Only two subjects, who were unable to swallow the tubes, were excluded from the study.

\section{METHODS}

Duodenal tube and infusions

To deliver duodenal infusions, a thin (OD 2.8 mm (8 FR), length $109 \mathrm{~cm}$ ) flexible polyvinyl tube (Merck Biomaterials, Alton, UK) was inserted through the nose into the small intestine. The tube was equipped with a side port approximately $5 \mathrm{~cm}$ from its tip. The infusion port was positioned approximately $15 \mathrm{~cm}$ distal to the pylorus, and the correct position of the tube was verified fluoroscopically. The following solutions were used during the studies: isotonic saline, $10 \%$ and $20 \%$ lipid emulsion (Intralipid 10\% and 20\%; Pharmacia AG, Dübendorf, Switzerland; $260 \mathrm{mosmol} / \mathrm{kg}$; energy density 1.1 or $2 \mathrm{kcal} / \mathrm{ml}$, respectively, con- taining $10 \%$ or $20 \%$ fractionated soy bean oil, respectively, $1.2 \mathrm{~g}$ fractionated egg phospholipids, and $2.25 \mathrm{~g}$ glycerol). The solutions were infused at a rate of $1 \mathrm{ml} / \mathrm{min}$.

\section{Gastric tube and barostat}

Subjects swallowed a second highly flexible single lumen tube (OD $3.5 \mathrm{~mm}$, ID $2.8 \mathrm{~mm}$; Tygon Tubing, Upchurch Scientific, Oak Harbor, Washington, USA). To distend the proximal stomach, a flaccid thin walled polyethylene bag (capacity $1100 \mathrm{ml}$ ) was attached to and tightly wrapped around the distal end of the tube. The bag was positioned in the fundus of the stomach by distending it with air, carefully pulling it back until its passage was restricted by the lower oesophageal sphincter, and then pushed back in again by $2 \mathrm{~cm}$. In addition to assisting in the unfolding and positioning of the bag, this first distension also ensured reproducibility of the data obtained during all subsequent distensions carried out during the course of the study. It has previously been demonstrated that during a series of distensions, data become reproducible from the second distension onwards. ${ }^{44}$ The proximal end of the tube was connected via a three way tap to the measurement and balloon ports of a gastric barostat (Distender Series II, G\&J Electronics Inc., Willowdale, Ontario, Canada). The functioning of the barostat has been described in detail previously. ${ }^{15}$ In brief, it is capable of monitoring changes in gastric volume at a fixed pressure. Thus if the gastric wall relaxes, air is injected into the gastric bag to maintain the pressure, while air is withdrawn if the stomach contracts. In addition, distensions of the stomach can be carried out.

\section{Blood sampling (study A)}

Blood samples were obtained repeatedly throughout the study (fig 1) to determine plasma levels of CCK at baseline, every five minutes during duodenal infusions, and at the beginning and end of each distension. Samples were collected into chilled EDTA tubes, centrifuged at $2^{\circ} \mathrm{C}$ within 30 minutes of collection and stored at $-70^{\circ} \mathrm{C}$ until extraction. Plasma CCK was determined by a sensitive and specific radioimmunoassay, as described previously. ${ }^{16}$ The antibody used binds to all biologically active CCK peptides containing sulphated tyrosine with almost equal affinity. Sulphated gastrins cross reacted $<1 \%$ in the assay, while no cross reactivity was found with unsulphated gastrins or CCK-8. The mean detection limit of the assay was $0.3(0.1) \mathrm{pmol} / 1$ with a confidence limit of $95 \%$. The coefficients of variation were $5.6 \%$ at $0.67 \mathrm{pmol} / 1$ and $7.2 \%$ at $15.1 \mathrm{pmol} / 1$ for intra-assay variation, and $12.3 \%$ at $0.85 \mathrm{pmol} / 1$ and $15 \%$ at $14.8 \mathrm{pmol} / 1$ for interassay variation.

\section{Intravenous infusion of the $C C K-A$ receptor} antagonist dexloxiglumide (study B)

Either dexloxiglumide (Rotta Research Laboratorium SpA, Monza (MI), Italy) or $0.9 \%$ saline (placebo) was administered into a forearm vein. Dexloxiglumide, the (D-)enantiomer of loxiglumide, is responsible 
Study A

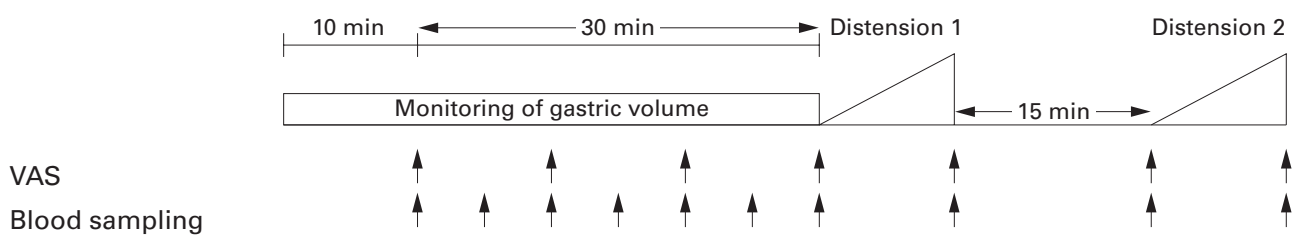

Study B

Duodenal infusion of lipid $20 \%(1 \mathrm{ml} / \mathrm{min})$

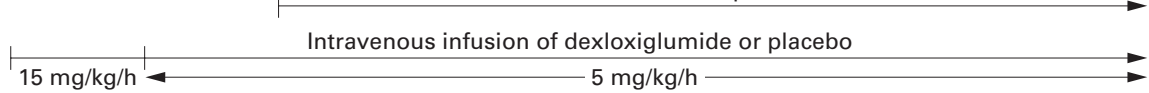

VAS

Figure 1 Experimental protocols for study $A$ (dose-response study) and study $B$ (cholecystokinin (CCK)-A receptor blockade). To determine the relationship between the lipid dose administered and severity of dyspeptic symptoms, six patients were studied on three occasions each, receiving duodenal infusion of $0.9 \%$ saline, or $10 \%$ or $20 \%$ lipid. Six healthy subjects were studied after infusion of $20 \%$ lipid only. During infusions, changes in gastric volume were assessed and the proximal stomach was distended in steps of $1 \mathrm{~mm} \mathrm{Hg/min} \mathrm{while} \mathrm{symptoms} \mathrm{were} \mathrm{monitored} \mathrm{and} \mathrm{plasma} \mathrm{CCK} \mathrm{levels} \mathrm{determined.} \mathrm{In}$ study $B, 12$ patients were studied twice to investigate the effect of CCK-A receptor blockade with dexloxiglumide on the symptomatic and gastric volume responses evoked by duodenal infusion of $20 \%$ lipid and gastric distension. VAS, visual analogue scale.

for the pharmacological activity of loxiglumide. ${ }^{17}$ During the first 10 minutes of the study, dexloxiglumide was infused at a rate of $15 \mathrm{mg} / \mathrm{kg} / \mathrm{h}$ to reach equilibrium. Subsequently, the rate was reduced to $5 \mathrm{mg} / \mathrm{kg} / \mathrm{h}$ for the remainder of the study to maintain adequate drug plasma levels throughout the study ensuring complete and selective blockade of CCK-A receptors. The dose of dexloxiglumide used in the present study was based on previous data using the related compound loxiglumide. Loxiglumide is approximately half as potent as dexloxiglumide but has been shown to produce almost complete and selective blockade of CCK-A receptors at a dose of $10 \mathrm{mg} / \mathrm{kg} / \mathrm{h}^{18}$

EXPERIMENTAL PROTOCOL

All studies were carried out at least six days and no more than 16 days apart, and each study took approximately four hours. For study A, examinations were performed at lunch time, at least four hours after breakfast, and for study B in the morning after an overnight fast. In study A, patients were allowed a light breakfast consisting of coffee or tea, two thin slices of bread, butter, and jam. Thereafter, only water was allowed up to one hour prior to the study. Once the tubes and intravenous catheter were in place, subjects were comfortably seated in an upright position on a hospital bed and the study protocol (fig 1) commenced. Initially, the minimal distending pressure (MDP) was determined by raising intrabag pressure with the barostat in steps of $1 \mathrm{~mm} \mathrm{Hg} / \mathrm{min}$. MDP has previously been defined as the pressure that is necessary to overcome intra-abdominal pressure resulting in a bag volume of at least 30 $\mathrm{ml}$. Intragastric pressure was set at MDP and volume was monitored until a stable recording was obtained for at least 10 minutes (baseline). MDP prior to the start of any duodenal infusion was 8 (1) $\mathrm{mm} \mathrm{Hg}$ and did not differ between study days or between healthy subjects and patients.

Study A: dose-response study

To determine the relationship between the dose of lipid administered and severity of dyspeptic symptoms, six patients were studied on three occasions each. They received a duodenal infusion of either isotonic saline, or $10 \%$ or $20 \%$ lipid in a randomised order following a Latin square design. Patients were blinded as to the nature of all infusions and the investigator performing the studies was blinded as to which lipid emulsion he had administered. Six healthy subjects were studied during infusion of $20 \%$ lipid only. During the lipid infusions, an energy load of approximately 70 or $120 \mathrm{kcal}$ (corresponding to 1.1 or $2 \mathrm{kcal} / \mathrm{min}$ for $10 \%$ and $20 \%$ lipid, respectively) was administered. An energy delivery of $2 \mathrm{kcal} / \mathrm{min}$ approximates the normal gastric emptying rate, and the lower dose was chosen to establish a dose-response relationship. During infusions, changes in proximal gastric tone (as changes in intrabag volume) were assessed for 30 minutes. Then, MDP was determined again, followed by two isobaric distension periods separated by 15 minutes. MDP was not significantly lowered by any of the infusions in patients but decreased to 6 (1) $\mathrm{mm} \mathrm{Hg}$ after infusion of $20 \%$ lipid in healthy subjects $(p<0.05)$. For distensions, $1 \mathrm{~mm} \mathrm{Hg}$ stepwise increases in intrabag pressure (starting at the initially determined MDP) were performed while volumes at the different pressure steps were monitored. Each pressure level was maintained for one minute. We chose a stepwise increasing (ramp) as 
opposed to a random distension protocol for three main reasons. Firstly, the ramp protocol most closely mimics gastric distension during food ingestion. Secondly, as patients were not explicitly told that "their stomachs would be distended" but were informed that during the study gastric pressures and volumes would be assessed or manipulated, subjects were not able to anticipate when or that a distension was carried out. Thirdly, we feared that randomly exposing patients to painfully high distension stimuli (as may be the case with random distension protocols) might lead to anxiety and hypervigilance resulting in a reduction in sensory thresholds. ${ }^{19}$

Study B: CCK-A receptor blockade study

Twelve patients (including the six subjects from study A) were studied on two occasions each to investigate the effect of CCK-A receptor blockade on the symptomatic response to duodenal infusion of $20 \%$ lipid and gastric distension. The study followed a double blind placebo controlled design, and the two study conditions were carried out in a randomised order. Intravenous administration of the CCK-A receptor antagonist dexloxiglumide or placebo commenced immediately after the baseline recording at a rate of $15 \mathrm{mg} / \mathrm{kg} / \mathrm{h}$ for 10 minutes (equilibrium), was then reduced to $5 \mathrm{mg} / \mathrm{kg} / \mathrm{h}$ for 10 minutes (steady state), and continued at this rate for the duration of the study. Duodenal infusion of lipid was then started and the protocol followed as described for study A.

\section{ASSESSMENT OF SYMPTOMS}

The severity of symptoms of fullness, bloating, epigastric discomfort, pain, and nausea was assessed at baseline and every 10 minutes during duodenal infusions, and at the beginning and the end of each distension on visual analogue scales (VAS). In addition, during one of the two distensions, symptoms were assessed every minute at the end of each distension step to obtain a continuous progression of symptoms with increasing distension. The VAS consisted of a $10 \mathrm{~cm}$ line, with $0 \mathrm{~cm}$ representing "sensation not present" and $10 \mathrm{~cm}$ "strongest sensation ever felt". ${ }^{20}$ Distensions were discontinued as soon as the subjects rated any of the sensations at " 9 " on the VAS, indicating severe discomfort. A sum of symptoms score was obtained for infusion and distension periods, respectively, by adding scores obtained from all symptoms over time in individual subjects. This score was only used in the "abstract" to summarise the differences between treatments.

To minimise the influence of visual or auditory cues on perception data, the barostat device and infusion pump were placed behind the subject's back, and the barostat was kept running continuously (that is, even during breaks in the protocol) to maintain a constant level of noise. In addition, subjects were not aware of the timing of any of the procedures. For example, it was not specified when distensions were carried out.
DATA ANALYSIS

Gastric volume changes

To evaluate changes in gastric volume during the different experimental conditions, the volume readings obtained during the baseline recording (10 minutes), during the 30 minutes of duodenal lipid or saline infusions and, in study B, additionally during the equilibrium and steady state periods, were averaged, and areas under the curves (AUC) were calculated.

\section{Gastric distensions}

During distensions, intragastric volumes during consecutive pressure steps were calculated by averaging the volume readings obtained during the last 30 seconds of each pressure step. These data were then used to construct pressure-volume profiles. Any differences between the volume profiles obtained during gastric distensions and the experimental conditions in studies A and B, respectively, were characterised by AUCs and slopes of the volume profiles. Because the procedures had to be discontinued at levels that varied between individuals, especially during gastric distensions, data sets from individuals were only analysed up to $\mathrm{MDP}+3 \mathrm{~mm} \mathrm{Hg}$, the highest common pressure step tolerated by all subjects during all experimental conditions. As analysis of MDPs assessed at various time points during the study revealed that duodenal lipid decreased MDPs over time, all data were referred to the initial MDP obtained at the beginning of each study day, and data from the two distensions were averaged.

\section{Sensory responses}

During infusions, AUCs (over 30 minutes) of the VAS scores were used to compare the effects of the different duodenal infusions on symptoms. During distensions, AUCs for the symptom profiles, obtained during the distension, during which symptoms were assessed at each distension step, were calculated between $\mathrm{MDP}$ and MDP+3 $\mathrm{mm} \mathrm{Hg}$.

\section{CCK responses}

During infusions, AUCs of plasma CCK levels were calculated. During distensions, plasma levels at the beginning and end of distensions were compared. Data from the two distensions were averaged.

\section{STATISTICAL ANALYSIS}

Data from study A were analysed by ANOVA. If statistically significant group differences were obtained $(p<0.05)$, paired comparisons were carried out using the Student's $t$ test. Data from patients and healthy subjects obtained during the $20 \%$ lipid infusion were compared using an unpaired $t$ test. Multiple comparisons were accounted for by applying a Bonferroni correction. Data from study B were analysed using the Student's $t$ test. Data are presented as mean (SEM). 


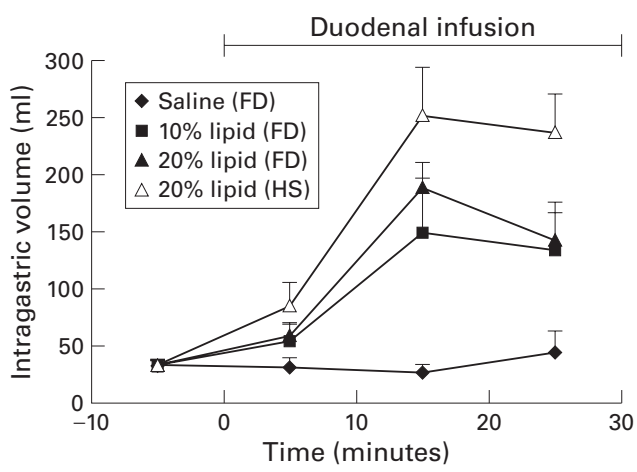

Figure 2 Gastric volume responses to duodenal infusion of isotonic saline, or $10 \%$ or $20 \%$ lipid in patients with functional dyspepsia (FD) and to infusion of $20 \%$ lipid in healthy subjects (HS) $(n=6)$.

\section{Results}

STUDY A: DOSE-RESPONSE STUDY

Responses to duodenal infusions prior to gastric distension

Gastric volume changes (fig 2, table 1). Duodenal infusion of $10 \%$ and $20 \%$ lipid caused a comparable increase in intrabag volume and AUC values: $20 \%$ lipid increased gastric volume more in healthy subjects than in patients $(\mathrm{p}<0.05)$.

Plasma CCK (fig 3). Baseline plasma levels (pmol/1) did not differ between study conditions (saline $0.8(0.3) ; 10 \%$ lipid $1.2(0.3)$; $20 \%$ lipid $1.7(0.7) ; \mathrm{p}>0.05)$ or between patients and healthy subjects $(2.6(0.8) \mathrm{pmol} / \mathrm{l}$; $\mathrm{p}>0.05)$. Duodenal infusion of both $10 \%$ and $20 \%$ lipid, but not of saline, raised plasma CCK levels but only the increase during infusion of $20 \%$ lipid reached statistical significance. Plasma CCK levels were similar in patients and healthy subjects during infusion of $20 \%$ lipid.

Symptom scores (fig 4A). There were no significant differences between study conditions for any of the symptoms assessed.

Responses to duodenal infusions with gastric distension

Gastric pressure-volume relationship (table 1). Infusion of both lipid emulsions caused a greater increase in intrabag volumes at a given pressure compared with saline $(\mathrm{p}<0.05)$. The slope of the pressure-volume profiles increased in patients with increasing amount of lipid administered, indicating an increase in compliance. In healthy subjects, $20 \%$ lipid caused a greater increase in intragastric volumes during gastric distension than in patients $(p<0.05)$. The slope of the pressure-volume profile

Table 1 Gastric responses to gastric distension and duodenal infusion of saline, or $10 \%$ or $20 \%$ lipid (study A)

\begin{tabular}{|c|c|c|c|c|}
\hline & \multicolumn{3}{|l|}{ Patients } & \multirow{2}{*}{$\begin{array}{l}\text { Healthy subject } \\
20 \% \text { lipid }\end{array}$} \\
\hline & Saline & $10 \%$ lipid & $20 \%$ lipid & \\
\hline \multicolumn{5}{|c|}{ Gastric volume changes during duodenal infusion } \\
\hline $\mathrm{AUC}\left(\mathrm{mm} \mathrm{Hg}^{\star} \mathrm{ml}\right)$ & $1222(271)$ & 3823 (413)†‡ & $3954(884) \dagger$ & $5786(910)$ \\
\hline \multicolumn{5}{|c|}{ Pressure-volume relationship during gastric distension } \\
\hline $\mathrm{AUC}\left(\mathrm{mm} \mathrm{Hg}^{\star} \mathrm{ml}\right)$ & $276(40)$ & $571(106) \dagger$ & $736(80) \dagger \ddagger$ & $1068(148)$ \\
\hline Slope $(\mathrm{ml} / \mathrm{mm} \mathrm{Hg})$ & $42(8)$ & $66(10)$ & $80(16)+\ddagger$ & $96(9)$ \\
\hline
\end{tabular}

Data are mean (SEM), $\mathrm{n}=6$.

Significantly different from tsaline, thealthy subjects, $\mathrm{p}<0.05$.

AUC, area under the curve.

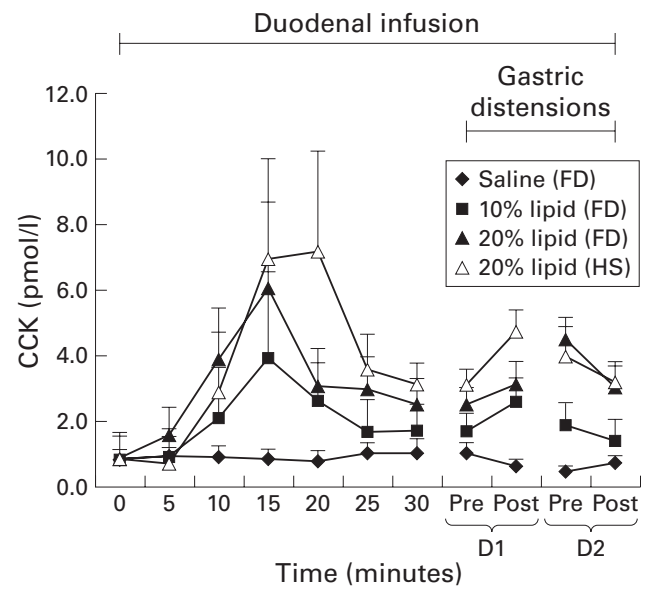

Figure 3 Plasma cholecystokinin (CCK) levels (baseline levels normalised) obtained in response to duodenal infusion of isotonic saline, or $10 \%$ or $20 \%$ lipid $(n=6)$ in patients with functional dyspepsia (FD) and healthy subjects (HS) before and during gastric distensions. The value at $t=20$ minutes in healthy subjects is due to one outlier. D1, distension $1 ; D 2$, distension 2 .

during infusion of $20 \%$ lipid was greater in healthy subjects than in patients $(\mathrm{p}<0.05)$.

Plasma CCK (fig 3). Gastric distension did not result in a further increase in plasma CCK levels (pmol/1) in patients (saline pre 0.77 (0.22); saline post 0.69 (0.21); 10\% lipid pre 1.81 (0.69); $10 \%$ lipid post 2.03 (0.62); $20 \%$ lipid pre 3.51 (0.61); 20\% lipid post $3.10(0.68)$ ) or healthy subjects $(20 \%$ lipid pre 3.55 (0.71), $20 \%$ lipid post $3.97(0.65)$ ). Thus CCK concentrations remained at levels comparable with those found prior to distensions.

Symptom scores (fig 4B). During distensions, symptoms of fullness, epigastric discomfort, and nausea paralleled the increase in intragastric pressure and showed a tendency to increase with the rising dose of lipid administered, but the differences were not statistically significant. Symptoms experienced by patients during infusion of $20 \%$ lipid were higher than in healthy subjects, reaching statistical significance for symptoms of fullness and pain $(\mathrm{p}<0.05)$.

STUDY B: CCK-A RECEPTOR BLOCKADE STUDY Responses to duodenal infusions prior to gastric distension

Gastric volume changes (table 2). Intravenous infusion of placebo or dexloxiglumide alone did not affect intragastric volumes (placebo 27 (4) $\mathrm{ml}$; dexloxiglumide 28 (6) $\mathrm{ml}$ ). Duodenal infusion of $20 \%$ lipid resulted in an increase in intragastric volume after placebo (186 (49) ml) which was completely prevented by dexloxiglumide (17 (9) $\mathrm{ml}$ ). This difference was also reflected in the AUC values.

Symptom scores (fig 5A). Infusion of dexloxiglumide or placebo alone did not induce dyspeptic symptoms. Duodenal lipid, when given with placebo, caused a slight but continuous increase in symptoms while dexloxiglumide completely abolished this effect. The differences between the two treatments reached statistical significance $(\mathrm{p}<0.05)$ for fullness (AUCs: dexloxiglumide 52 (10); placebo 76 (17)), discomfort (dexloxiglumide 35 (11), 


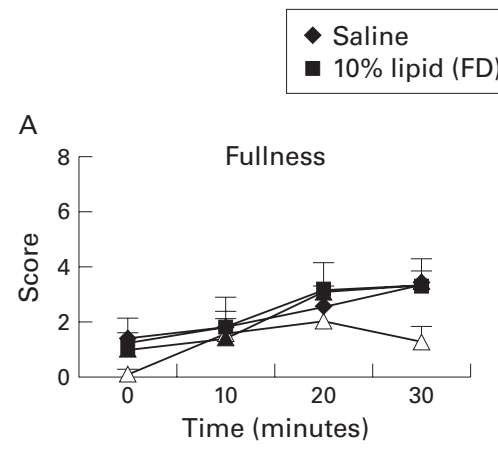

\ $20 \%$ lipid (FD)

$\triangle 20 \%$ lipid (HS)

A
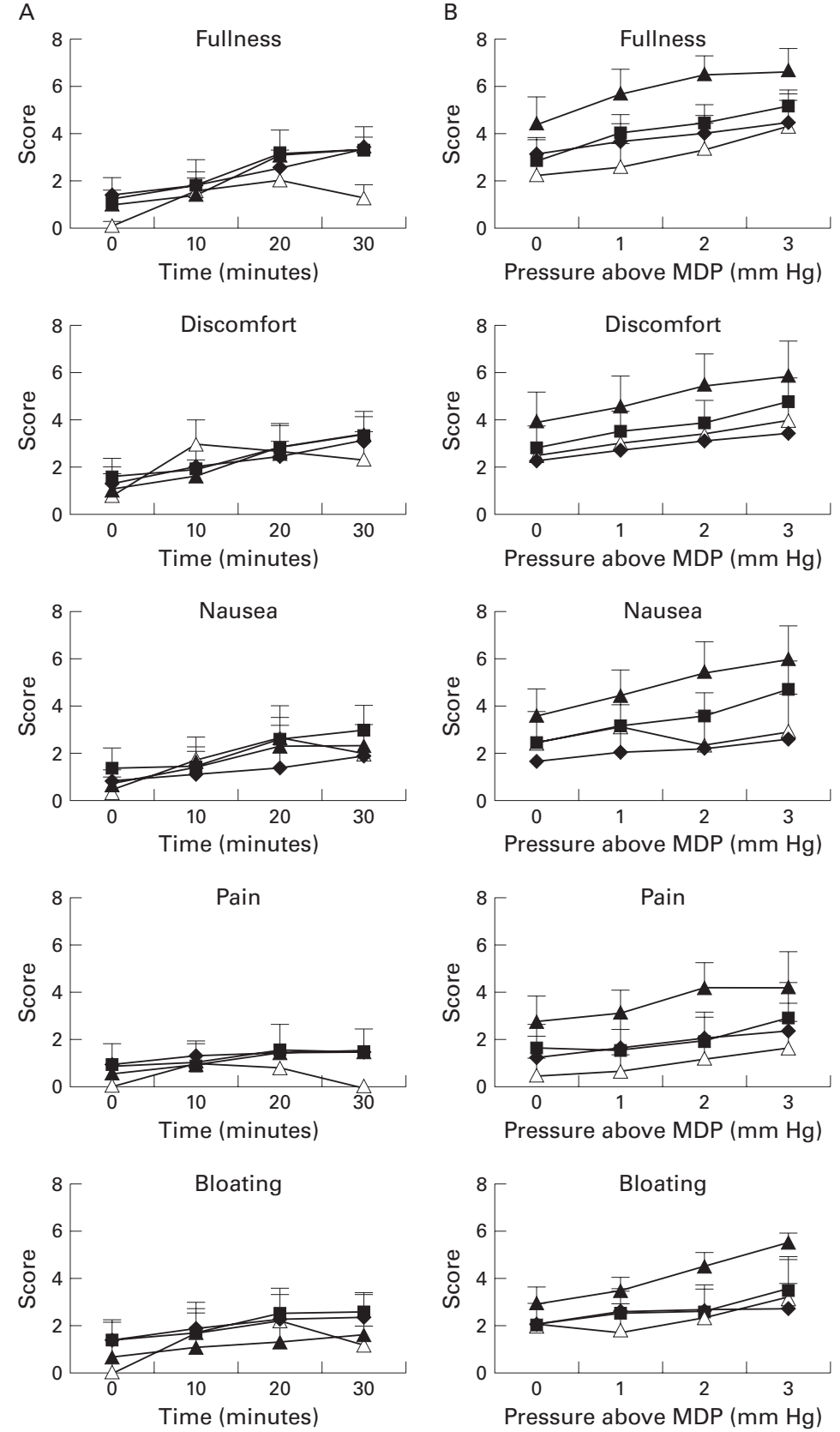

Figure 4 Scores for dyspeptic symptoms during duodenal infusion of isotonic saline, or $10 \%$ or $20 \%$ lipid in patients with functional dyspepsia (FD) and $20 \%$ lipid in healthy subjects (HS) (A) and when infusions were combined with gastric distension (B).

placebo 71 (19)) and nausea (dexloxiglumide 25 (8); placebo 68 (19)).

Responses to duodenal infusions with gastric distension

Gastric pressure-volume relationship (table 2). Intrabag volumes, expressed as AUC values, and the slope of the pressure-volume profiles were greater when lipid was given with intravenous placebo than when given with dexloxiglumide $(\mathrm{p}<0.05)$, indicating a decrease in gastric compliance during dexloxiglumide.

Symptom scores (fig 5B). During distensions, dyspeptic symptoms developed with the in-
Table 2 Gastric responses to gastric distension and duodenal infusion of $20 \%$ lipid, with intravenous infusion of dexloxiglumide or placebo (study B)

\begin{tabular}{|c|c|c|}
\hline & $\begin{array}{l}\text { Placebo } \\
+20 \% \text { lipid }\end{array}$ & $\begin{array}{l}\text { Dexloxiglumide } \\
+20 \% \text { lipid }\end{array}$ \\
\hline \multicolumn{3}{|c|}{ Gastric volume changes during duodenal infusion } \\
\hline $\mathrm{AUC}\left(\mathrm{mm} \mathrm{Hg}^{\star} \mathrm{ml}\right)$ & $4970(982)$ & $1120(270) \dagger$ \\
\hline \multicolumn{3}{|c|}{ Pressure-volume relationship during gastric distension } \\
\hline $\mathrm{AUC}\left(\mathrm{mm} \mathrm{Hg}{ }^{\star} \mathrm{ml}\right)$ & $565(83)$ & $209(39) \dagger$ \\
\hline Slope $(\mathrm{ml} / \mathrm{mm} \mathrm{Hg})$ & $72(11)$ & $51(7) \dagger$ \\
\hline
\end{tabular}

Data are mean (SEM), $\mathrm{n}=12$.

†Significantly different from placebo, $\mathrm{p}<0.05$.

AUC, area under the curve.

crease in intragastric pressure and were greater during infusion of placebo than of dexloxiglumide. The differences were statistically significant $(\mathrm{p}<0.05)$ for fullness (AUCs: dexloxiglumide 10 (2); placebo 14 (2)), bloating (dexloxiglumide 6 (2); placebo 11 (3)), discomfort (dexloxiglumide 8 (2); placebo 15 (4)), and nausea (dexloxiglumide 4 (2); placebo $14(4)$ ).

Volume and pressure thresholds for discomfort. The volumes at which discomfort occurred during distensions were not different between the placebo (V: $513(48) \mathrm{ml}$ ) and dexloxiglumide (514 (47) $\mathrm{ml}$ ) groups. However, maximally tolerated pressures were higher during dexloxiglumide (p: 20 (1) $\mathrm{mm} \mathrm{Hg}$ ) than during placebo (16 (1) $\mathrm{mm} \mathrm{Hg} ; \mathrm{p}<0.05)$, suggesting decreased sensitivity to distension after dexloxiglumide.

\section{Discussion}

This study has demonstrated that gastrointestinal symptoms in patients with functional dyspepsia induced by duodenal lipid infusion and gastric distension can be relieved by administration of the CCK-A receptor antagonist dexloxiglumide, indicating that CCK-A receptor mechanisms are involved in the generation of fat induced dyspeptic symptoms. Dexloxiglumide abolished induction of dyspeptic symptoms by lipid, reduced the severity of symptoms in response to duodenal lipid combined with gastric distension, and also reduced the sensitivity to distension. Our observations emphasise the involvement of fat in the pathophysiology of functional dyspepsia.

Evidence for an association between lipid induced dyspeptic symptoms and release of endogenous CCK comes from the first part of our study in which we investigated symptomatic and plasma CCK responses to two doses of duodenal lipid. We found that both severity of symptoms and plasma CCK levels were increased in patients in a dose related fashion. As plasma CCK levels in patients were not different from those in healthy subjects during infusion of the $20 \%$ lipid emulsion, CCK hypersecretion in patients can be excluded as an underlying mechanism. Plasma CCK levels comparable with those in healthy subjects more likely indicate the existence of hypersensitivity to CCK in patients. Accordingly, hypersensitivity to intravenously administered CCK has been described in patients with functional dyspepsia. ${ }^{13}$ Although it is uncertain if CCK when given intravenously adequately reproduces the responses to endogenously released CCK and induces gastrointestinal sensations and symp- 


\section{- Placebo $\bigcirc$ Dexloxiglumide}

A
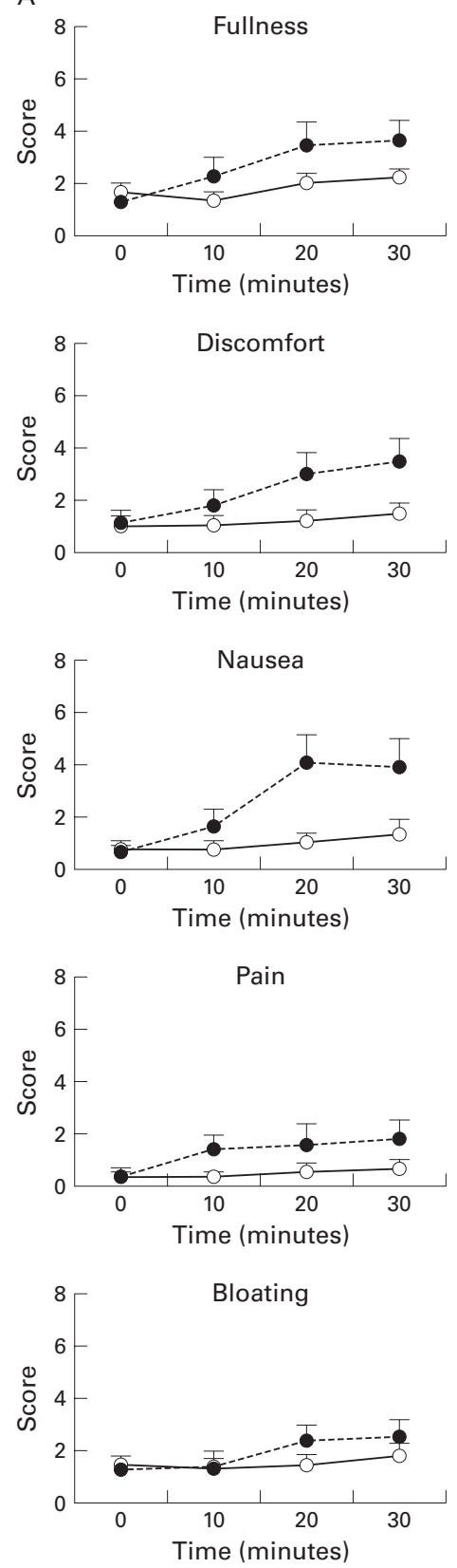

B
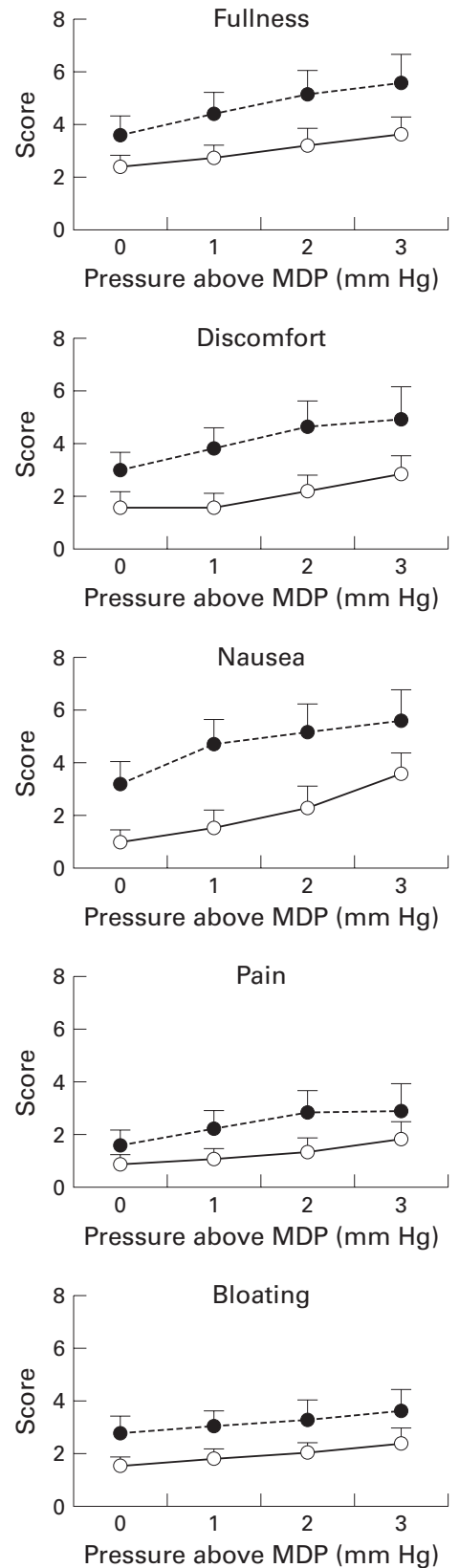

Figure 5 Scores for dyspeptic symptoms during duodenal infusion of $20 \%$ lipid given with intravenous placebo or dexloxiglumide in patients with functional dyspepsia $(A)$ and when infusions were combined with gastric distension (B).

toms via the same mechanisms, data from both studies indicate the possibility of such a hypersensitivity reaction. The second line of evidence is derived from the second part of our study in which the selective CCK-A receptor antagonist dexloxiglumide eliminated dyspeptic symptoms during lipid infusion alone and significantly improved symptoms during lipid infusion plus gastric distension in the patient group. These results indicate that endogenous CCK is involved in the pathophysiology of functional dyspepsia via activation of CCK-A receptors. CCK may act in a paracrine fashion - that is, in close proximity to the site of its release where the CCK concentration is very

high and this information can be conveyed to the central nervous system via vagal afferent fibres. As this pathway is also involved in the feedback inhibition of gastric tone and motility, it is conceivable that gastric motor changes also indirectly affect symptoms. However, our previous data suggest that symptom development is not closely related to specific gastric motor changes. ${ }^{4}$ CCK may activate CCK receptors located in the mucosa and muscle layers of the gastric wall. CCK-A receptor immunoreactivity has recently been described on rat gastric myenteric neurones and on fibres in the mucosa and muscle. ${ }^{21}$ However, it is not clear whether circulating CCK concentrations are sufficient to activate gastric CCK receptors. In addition, we cannot exclude the involvement of a central effect of CCK as we used a receptor antagonist specific for CCK-A receptors known to be located preferentially in the periphery.

Activation of CCK-A receptors does not fully explain dyspeptic symptoms induced during gastric distension and duodenal lipid, as blockade of these receptors improved but did not entirely abolish symptoms. CCK-A receptor antagonism during duodenal lipid infusion and gastric distension may prevent sensitisation by CCK of a stomach that is already sensitive to distension but not directly improve mechanical hypersensitivity. Other CCK independent mechanisms may also be involved. Free fatty acids may cause transient irritation of the intestinal mucosa ${ }^{22}{ }^{23}$ leading to release of neuromodulators such as serotonin which may contribute to nausea, as has been shown previously. ${ }^{24}$ The irritant effect of bile acids may also cause dyspeptic symptoms.

Our finding that blockade of CCK-A receptors improved dyspeptic symptoms during gastric distension and duodenal lipid infusion has potentially important implications for the treatment of patients with functional dyspepsia. Preliminary studies in this group of patients $\mathrm{s}^{25}$ and in patients with irritable bowel syndrome ${ }^{26}$ have shown a significant improvement in symptoms during treatment with the CCK-A antagonist loxiglumide. The availability of orally administered CCK-A antagonists may therefore offer a new approach to the treatment of functional dyspepsia. Further studies in larger patient groups are required to assess the potential therapeutic effect of CCK antagonists. However, it should also be pointed out that patients with functional dyspepsia suffer from symptoms in the fasted state, indicating that a trigger other than "postprandial" stimuli, such as gastric distension and duodenal nutrients as used in our experimental model, may be involved and require attention in the treatment of this condition.

Gastric relaxation in response to duodenal lipid infusion, reflected by an increase in intrabag volume, and compliance of the gastric wall during gastric distensions were less in patients than in healthy subjects. Impairment of gastric accommodation in response to food has been described previously and discussed as a contributing factor to symptomatology. ${ }^{27-29}$ However, we found that dyspeptic symptoms were 
less intense and visceral sensitivity decreased, despite the fact that gastric relaxation was blocked and gastric compliance reduced by the CCK-A antagonist. This observation is in contrast with what would be expected based on previous findings and challenges whether reduced gastric accommodation is a primary factor in the pathophysiology of functional dyspepsia or rather merely an epiphenomenon. As we did not find any differences in gastric compliance between the two lipid doses in patients but observed a dose related effect of the lipid infusions on dyspeptic symptoms, we postulate that small intestinal receptors are involved in the pathophysiology of functional dyspepsia. This conclusion is supported by our previous studies ${ }^{4812}$ demonstrating that activation of small intestinal receptors by increasing luminal nutrient concentrations, particularly fat, powerfully modulates visceral sensitivity and the symptomatic response to gastric distension. These previous data together with the present study emphasise the importance of chemoreceptive modulation of visceral sensitivity and symptomatology.

Despite significantly enhancing symptoms, gastric distension did not increase plasma CCK levels further in patients or healthy subjects. This finding is in contrast with data from another study in humans ${ }^{30}$ in which an $81 \%$ increase in plasma CCK was observed after fundic distension. In contrast, antral distension does not appear to cause CCK secretion. ${ }^{30} 31$ The lack of effect of fundic distension in our own study may be due to the fact that duodenal lipid already induced marked (100-400\%) increases in plasma CCK levels prior to distension and therefore no additional CCK release may have occurred during distensions. However, gastric distension alone did not cause an increase in plasma CCK during duodenal infusion of the saline control solution. Hence our data do not support the notion that gastric distension is a stimulus for CCK release.

Anxiety and hypervigilance may also have an influence on symptom severity and gastrointestinal perception. ${ }^{32}$ However, we did not find any differences in the data of patients participating in studies A and B. Both symptom severity and perception could have been increased in study $\mathrm{B}$, due to expectation and hypervigilance, or reduced because patients had become familiar with the procedures during study $\mathrm{A}$; neither was the case. We chose ramp distensions in our protocol as this distension mode most closely reflects gastric distension during food intake. In addition, it has been demonstrated recently in the oesophagus that the perception of stimuli is enhanced with an irregular stimulus presentation, perhaps as a result of anxiety and fear of sudden discomfort. ${ }^{19}$

In summary, our data demonstrated that the effects of duodenal lipid on dyspeptic symptoms during gastric distension increased with the dose of lipid administered and were paralleled by increases in plasma CCK levels. CCK-A receptor blockade by dexloxiglumide markedly diminished the response, indicating that CCK-A dependent mechanisms are involved in the pathophysiology of functional dyspepsia. Our findings may provide a rationale for the treatment of functionally dyspeptic patients with CCK-A antagonists.

Parts of the data have previously been published in abstract form (Feinle C, Meier O, D'Amato M, et al. Neurogastroenterol Motil 1998;10:464 and Feinle C, Meier O, D'Amato M, et al. Gastroenterology 1999;116 (4pt2):A992). The study was supported by a grant (No 32-56068.98) from the Swiss National Science Foundation and by Kamillo-Eisner-Stiftung, Hergiswil, Switzerland.

1 Bradette M, Pare P, Douville P, et al. Visceral perception in health and functional dyspepsia. Dig Dis Sci 1991;36:52-8.

2 Lemann M, Dedering JP, Flouriè B, et al. Abnormal perception of visceral pain in response to gastric distension in chronic idiopathic dyspepsia. Dig Dis Sci 1991;36:1249-54.

3 Mearin F, Cucula M, Azpiroz F, et al. The origin of symptoms on the brain-gut axis in functional dyspepsia. Gastroenterology 1991;101:999-1006.

4 Feinle C, Grundy D, Read NW. Effects of duodenal nutrients on sensory and motor responses of the human nutrients on sensory and motor responses of the hum

5 Houghton LA, Mangnall YF, Dwivedi A, et al. Sensitivity to nutrients in patients with non ulcer dyspepsia. Eur $\mathcal{f}$ nutrients in patients with non ulcer
Gastroenterol Hepatol 1993;5:109-13.

6 Taggart D, Billington BP. Fatty foods and dyspepsia. Lancet 1966;2:465-6.

7 Barbera R, Feinle C, Read NW. Abnormal sensitivity to duodenal lipid in patients with functional dyspepsia. Eur $\mathcal{F}$ Gastroenterol Hepatol 1995;7:1051-7.

8 Barbera R, Feinle C, Read NW. Nutrient-specific modulation of gastric mechanosensitivity in patients with functional dyspepsia. Dig Dis Sci 1995;40:1636-41.

9 Hopman WPM, Jansen JBMJ, Lamers CBHW. Comparative study of the effects of equal amounts of fat, protein and starch on plasma cholecystokinin in man. Scand 7 Gastroenterol 1985;20:843-7.

10 Lieverse RJ, Jansen JBMJ, Lamers CBHW. Cholecystokinin and satiation. Neth 7 Med 1993;42:146-52.

11 Miaskiewicz SL, Stricker EM, Verbalis JG. Neurohypophyseal secretion in response to cholecystokinin but not mealinduced gastric distension in humans. $\mathcal{f}$ Clin Endocrinol Metab 1989;68:837-43.

12 Feinle C, D'Amato M, Read NW. CCK-A receptors modulate gastric sensory and motor responses to gastric distension and duodenal lipid. Gastroenterology 1996;110: 1379-85

13 Chua ASB, Dinan TG, Noonan N, et al. Cholecystokinin hyper-responsiveness in dysmotility-type non ulcer dyspepsia. Ann N Y Acad Sci 1994;713:298-9.

14 Mesquita MA, Thompson DG, Troncon LE, et al. Effect of cholecystokinin-A receptor blockade on lipid-induced gastric relaxation in humans. Am F Physiol 1997;273:G118-23.

15 Azpiroz F, Malagelada JR. Intestinal control of gastric tone. Am F Physiol 1985;249:G501-9.

16 Riepl RL, Fiedler F, Ernstberger M, et al. Effect of intraduodenal taurodeoxycholate and L-phenylalanine on pancreatic secretion and on gastroenteropancreatic peptide atic secretion and on gastroenteropancreatic

17 D'Amato M, Rovati LC. Cholecystokinin-A receptor antagonists: therapies for gastrointestinal disorders. Exp antagonists: therapies for gastrointe
Opin Invest Drugs 1997;6:819-36.

18 Niederau C, Heintges T, Rovati LC, et al. Effects of loxiglumide on gallbladder emptying in man. Gastroenterology 1989;97:1331-6.

19 Hollerbach S, May A, Bulat R, et al. The perception of oesophageal stimuli is enhanced with an irregular stimulus presentation. Neurogastroenterol Motil 1999;11:264.

20 Sepple CP, Read NW. Gastrointestinal correlates of the development of hunger in man. Appetite 1989;13:183-91.

21 Sternini C, Wong H, Pham T, et al. Expression of cholecystokinin A receptors in neurons innervating the rat stomach and intestine. Gastroenterology 1999;117:1136-46.

22 Velasquez OR, Henninger K, Fowler M, et al. Oleic acid-induced mucosal injury in developing piglet intestine. acid-induced mucosal injury in de

23 Kvietys PR, Specian RD, Grisham MB, et al. Jejunal Kvietys PR, Specian RD, Grisham $\mathrm{MB}$, et al. Jejunal
mucosal injury and restitution: role of hydrolytic products of food digestion. Am f Physiol 1991;261:G384-91.

24 Andrews PLR, Davis CJ, Bingham S, et al. The abdominal visceral innervation and the emetic reflex: pathways, pharmacology and plasticity. Can F Physiol Pharmacol 1990;68: 325-45.

25 Chua ASB, Bekkering M, Rovati LC, et al. Clinical efficacy and prokinetic effect of the CCK-A antagonist loxiglumide in nonulcer dyspepsia. Ann N Y Acad Sci 1994;713:451-3.

26 Cann PA, Rovati LC, Smart HL, et al. Loxiglumide, a CCK-A antagonist, in irritable bowel syndrome. A pilot mulit-centre clinical study. Ann N Y Acad Sci 1994;713: 449-50.

27 Troncon LEA, Bennett RJM, Ahluwalia NK, et al. Abnormal intragastric distribution of food during gastric emptying in functional dyspepsia patients. Gut 1994;35: 327-32.

28 Gilja OH, Hausken T, Wilhelmsen I, et al. Impaired accommodation of proximal stomach to a meal in functional dyspepsia. Dig Dis Sci 1996;41:689-96. 
29 Tack J, Piessevaux H, Coulie B, et al. Role of impaired gastric accommodation to a meal in functional dyspepsia. Gastroenterology 1998;115:1586-7.

30 Koop I, Ruppert-Seipp G, Koop H, et al. Cholecystokinin release by gastric distension - an atropine-sensitive mechanism. Digestion 1990;46:220-7.
31 Kreiss C, Schwizer W, Erlacher U, et al. Role of antrum in regulation of pancreaticobiliary secretion in humans. $A m \mathcal{F}$

32 Naliboff BD, Munakata J, Fullerton S, et al. Evidence for two distinct perceptual alterations in irritable bowel
syndrome. Gut 1997;41:505-12. 